\title{
The nature and incidence of injuries in a Currie Cup rugby team from 2001 to 2003
}

\author{
H B Millson (MPhil Sports Physiotherapy) ${ }^{1}$ \\ G D Hechter (BA Hons Biokinetics)' \\ K D Aginsky (BA Hons Biokinetics) ${ }^{2}$ \\ C Bolger (BSc Hons Sport and Exercise Science) ${ }^{2}$ \\ C J Saunders (BSc Chemical, Molecular and Cellular Biology) \\ ${ }^{1}$ Western Province Rugby (Pty) Ltd, PO Box 55, Newlands, Cape Town \\ ${ }^{2}$ Medical Research Council/University of Cape Town Research Unit for Exercise Science and Sports Medicine
}

\begin{abstract}
Objective. To describe the type and occurrence of injuries in a South African Currie Cup rugby team over 3 consecutive seasons (2001 - 2003), during which time strategies to reduce injuries were introduced by the management team consisting of the coaching and medical support staff.

Design. A retrospective, descriptive study.

Setting. All injuries, grade 1 and above, of 56 contracted, male players (age $25.1-2.8$ years) of a South African Currie Cup rugby team were recorded over 3 consecutive seasons.
\end{abstract}

Main outcome measures. Injury data collected included the type and mechanism of injury as well as the body part injured, the period of the season in which the injury occurred and whether the injury was a first episode or recurring injury. Injury rates are expressed as the number of injuries per 1000 hours at risk.

Results. The number of injuries increased as the season progressed. Strains $(N=56)$, sprains $(N=29)$ and contusions $(N=44)$ accounted for the majority of injuries each season, while the most injured body part was the lower limb. Direct injuries accounted for the majority of total injuries across all 3 seasons. The most important finding was a reduction in overall injury rate over the 3 seasons $(p<0.002)$.

Conclusions. These results suggest that preventive strategies implemented by team coaches and physiotherapists may reduce the number of injuries in rugby union, and continuous evaluation and management of training strategies is advised.

\section{CORRESPONDENCE:}

H Millson

PO Box 55

Newlands

7725

Tel: 021-659 4600

Fax: 021-659 4601

E-mail: helenmil@mweb.co.za

\section{Introduction}

There is concern expressed by the media and medical community about the high prevalence of injury among professional rugby players. ${ }^{14}$ An analysis of all injuries requiring medical attention during the 1995 Rugby Union World Cup, the last tournament before the start of the professional era, showed an injury rate of 32 injuries per 1000 player game hours. ${ }^{15}$ A prospective study of elite Australian rugby union players showed an increase in the number of injuries from 47 to 74 injuries per 1000 player hours of game play after the start of the professional era. ${ }^{1}$ In this study an injury was defined as a player being forced to either leave the field or miss a subsequent game. Although comparison of injury rates between studies is difficult because of lack of uniformity in the definition of injuries and injury rates, the relatively high incidence of injury since the introduction of professionalism in the game of rugby is a common theme. ${ }^{10}$

Rugby Union has the highest reported injury rate of all major sports played in New Zealand. ${ }^{4}$ The nature of the game requires players to make use of a wide range of fitness components, such as muscular strength and power, athletic endurance, speed, acceleration and agility. ${ }^{7}$ The incidence of injuries in rugby league, a similar but more physically demanding game than rugby union, has been shown to increase as the intensity, duration and load of training and match sessions increases. ${ }^{7,9}$ In addition, Lee at al. ${ }^{18}$ report that over a season there is a $3.9 \%$ increase in relative risk of injury for each week of additional pre-season training a player attends. These results suggest that training strategy and volume may significantly affect the injury rate of players over the season.

The income of professional players depends on their ability to play and perform during matches. Injured players have to take time off for treatment and recovery, with resultant loss of income, while the injuries themselves are associated with high medical costs. In addition, there is evidence that injuries associated with professional and semi-professional sporting activities predispose individuals to musculoskeletal diseases such as osteoarthritis later in life. ${ }^{19}$ Previous injuries have also been shown to be a risk factor for further injuries. ${ }^{22}$ There is, therefore, a need to identify strategies that min- 
imise the risk of both new and recurrent injuries in professional and semi-professional rugby players.

The aim of this retrospective study was to describe the type and occurrence of injuries in a South African Currie Cup rugby team over 3 consecutive seasons (2001 - 2003). During this time strategies to reduce injuries were introduced by the management team consisting of the coaching and medical support staff.

\section{Methods}

\section{Subjects}

The subjects $(N=56)$ in this study were all contracted male players (age 25.1 - 2.8 years, mean - standard deviation (SD)) in a South African Currie Cup rugby team studied over 3 consecutive seasons (2001 - 2003). In all 3 seasons the number of contracted players in the squad was the same $(N=40)$; however the individuals comprising the squad varied slightly/somewhat from season to season.

\section{The Currie Cup tournament}

Pre-season training began in June each season and included friendly matches (2001: $N=4 ; 2002: N=1 ; 2003: N=1$ ) not included in the Currie Cup tournament. The Currie Cup season then started in July and ended after the final match which was played in early November each year. The South African Currie Cup is a rugby tournament played by provincial rugby teams. The number of games played during the tournament varied each season depending on the team $s$ performance (2001: $N=12$; 2002: $N=10 ; 2003: N=14$ ). The players were given approximately 3 weeks off after their final Currie Cup match and thereafter participated in supervised off-season training. Players then received approximately 2 weeks off in May/June prior to pre-season training the following year.

Many of these players also competed in the Super 12 season which started in February and continued through to May. The injury data recorded does not include injuries sustained during the Super 12 tournament. However, all players underwent musculoskeletal evaluations after the tournament and any injuries diagnosed were excluded from this study.

\section{Data collection}

All players who sustained injuries during the $2001-2003$ seasons completed an injury evaluation form $(N=161$ injuries). The team physiotherapist coded all injury evaluation forms and researchers were unaware of the identity of the players, thereby maintaining confidentiality. The forms were completed either directly after, or within 5 days of an injury occurring. This depended on the timing of the injury or the time at which the player became aware of the injury. All injuries grade 1 and above were recorded and included in the analysis regardless of whether or not they prevented the player from training or playing in a match. A grade 1 injury was defined as one in which there was pain present with minimal loss of muscle function or strength, ${ }^{3}$ but which required the individual to seek medical attention. The recording and diagnosis of injuries was done under the guidance of the team physiotherapist who was employed for the full duration of the study. The injury evaluation forms recorded each players position and characteristics associated with the injury. The injuries were classified according to type and mechanism of injury, whether it was a first episode or recurring injury, the period of the season in which the injury occurred and the body part injured. A strain was defined as an-acute muscle injury whilst a sprain was defined as an acute ligament injury. ${ }^{3}$ Injuries such as medial tibial stress syndrome and facet joint pathology were grouped under other. Direct injuries were defined as traumatic injuries due to external forces, and indirect injuries were defined as those injuries due to sudden intrinsic overload, overuse or other contributing factors such as inadequate nutrition, musculoskeletal abnormalities, poor playing surfaces and environmental conditions.

\section{Injury rates}

Injury rates were calculated based on methods described previously. ${ }^{7,12,13}$ Matches were assumed to be 80 minutes (1.33 hours) in duration. The match injury exposure time (MIE) for each season for all players was calculated as: 1.33 houks $x 15$ players on the field $x$ number of matches in the season. Similar calculations were done to determine the MIE for forwards and backline players separately, assuming that during a match there are 8 forwards and 7 backline players on the field. Training injury exposure time (TIE) was calculated as: number of contracted players in the squad $x$ number of hours of supervised training per season. Supervised training was defined as that training which occurred under the direction of the team coach and/or conditioning coach. Total injury rate was calculated as the number of injuries sustained in a season divided by the sum of MIE and TIE. Injury rates were expressed as number of injuries per 1000 hours at risk. Match injury rates were expressed as number of injuries sustained during matches per 1000 hours of match play.

\section{Statistical analysis}

Differences in the incidence of injuries between categories for the 3 seasons were assessed using a Chi-squared test for trend. Statistical significance was accepted when $p<0.05$.

\section{Results}

In all 3 seasons the number of contracted players in the squad was the same (Table I). The average age of the players was $25.5-3.1,24.4-2.2$ and $25.5-2.8$ years (mean SD) for 2001, 2002 and 2003 respectively. There was a tendency for the number of injuries to increase as the season progressed (Fig. 1), with the highest number of injuries occurring in July $(N=19)$ and September $(N=18)$ in 2001 , September $(N=21)$ in 2002, and August $(N=8)$ in 2003 .

Table II shows a reduction in overall injury rate $(p<0.002)$ and the match injury rate $(p<0.0001)$ over the 3 seasons. 
TABLE $\mathrm{L}$. The number of injuries, and players injured, during each season

\begin{tabular}{lccccc} 
Season & $\begin{array}{c}\text { Number of contracted } \\
\text { players in squad }\end{array}$ & $\begin{array}{c}\text { Number of } \\
\text { players injured }\end{array}$ & $\begin{array}{c}\text { Recurrent injuries } \\
(\mathbf{N})\end{array}$ & $\begin{array}{c}\text { First-episode injuries } \\
(\mathrm{N})\end{array}$ & $\begin{array}{c}\text { Total injuries } \\
(\mathrm{N})\end{array}$ \\
\hline 2001 & 40 & 33 & 25 & 47 & 72 \\
2002 & 40 & 31 & 28 & 31 & 59 \\
2003 & 40 & 18 & 11 & 19 & 30 \\
\hline
\end{tabular}

\section{TABLE II. Training injury exposure time and total injury rate}

\begin{tabular}{|c|c|c|c|c|c|c|c|c|}
\hline & & \multicolumn{3}{|c|}{ Match injuries } & \multirow[b]{2}{*}{ TIE (hours) } & \multirow[b]{2}{*}{ Hours of training per match } & \multirow{2}{*}{\multicolumn{2}{|c|}{ Total injury rate ${ }^{\dagger}$}} \\
\hline \multicolumn{2}{|c|}{ Season } & $\begin{array}{c}\text { MIE } \\
\text { (hours) }\end{array}$ & $\begin{array}{l}\text { No. of } \\
\text { injuries }\end{array}$ & $\begin{array}{c}\text { Match } \\
\text { Injury rate* }\end{array}$ & & & & \\
\hline \multirow{2}{*}{2001} & Pre & 79.8 & \multirow{2}{*}{56} & \multirow{2}{*}{175.4} & 1880 & 11.8 & 7.7 & \multirow{2}{*}{8.1} \\
\hline & In & 239.4 & & & 6680 & 13.9 & 8.4 & \\
\hline \multirow{2}{*}{2002} & Pre & 20.0 & \multirow{2}{*}{40} & \multirow{2}{*}{182.2} & 2080 & 52.0 & 1.0 & \multirow{2}{*}{7.4} \\
\hline & in & 199.5 & & & 5640 & 14.1 & 10.0 & \\
\hline \multirow[t]{2}{*}{2003} & Pre & 20.0 & \multirow[t]{2}{*}{19} & \multirow{2}{*}{63.5} & 2000 & 50.0 & 1.5 & \multirow{2}{*}{3.7} \\
\hline & $\ln$ & 279.3 & & & 5880 & 10.5 & 4.2 & \\
\hline
\end{tabular}

Match injury exposure time (MIE); training injury exposure time (TIE).

Total injury rate expressed as number of injuries per 1000 hours at risk, match injury rate expressed as number of injuries per 1000 hours of match play.

* $\rho<0.0001$.

$p<0.002$.

TABLE III. The injury rate and number of direct and indirect injuries in both forwards and backline players.

\begin{tabular}{|c|c|c|c|c|c|c|c|c|}
\hline \multirow[b]{2}{*}{ Season } & \multicolumn{4}{|c|}{ Backline } & \multicolumn{4}{|c|}{ Forwards } \\
\hline & $\begin{array}{c}\text { Direct injuries } \\
(N)\end{array}$ & $\begin{array}{l}\text { Indirect injuries } \\
\text { (N) }\end{array}$ & Total & Injury rate * & $\begin{array}{l}\text { Direct injuries } \\
\text { (N) }\end{array}$ & $\begin{array}{c}\text { Indirect injuries } \\
\text { (N) }\end{array}$ & Total & Injury rate * \\
\hline 2001 & .29 & 12 & 41 & 4.7 & 22 & 10 & 32 & 3.7 \\
\hline 2002 & 18 & 12 & 30 & 3.8 & 15 & 14 & 29 & 3.7 \\
\hline 2003 & 12 & 6 & 18 & 2.2 & 8 & 4 & 12 & 1.5 \\
\hline
\end{tabular}

" $p<0.0001$

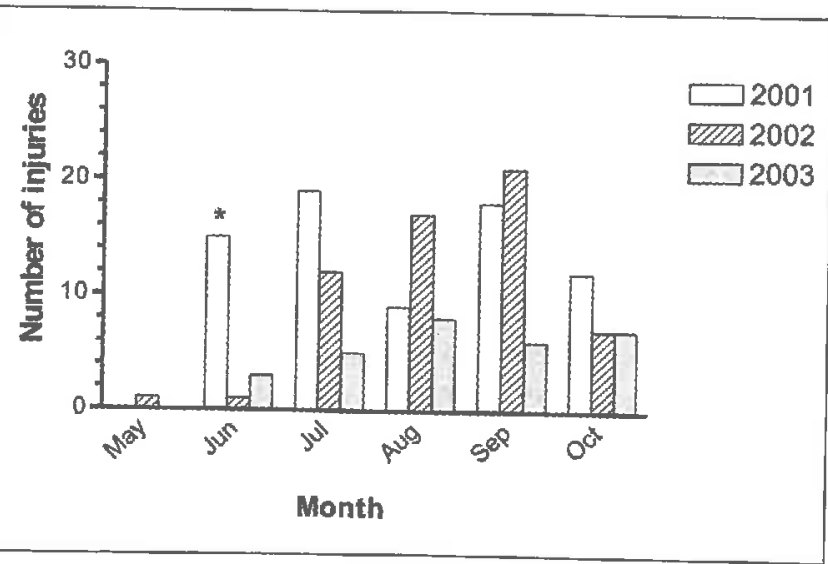

Fig 1. Number of injuries in each month from May to October (2001 - 2003) (* p < 0.05; June 2001 v. June 2002 and June 2003).
The total TIE was 8560,7720 and 7880 hours for 2001, 2002 and 2003 respectively, with 16 matches played in 2001, 11 matches in 2002 and 15 matches in 2003. Furthermore, there was a reduction in the ratio of training hours per match played during the in-season of 2003 (10.5 hours) compared with that in 2001 (13.9 hours) and 2002 (14.0 hours).

Direct injuries accounted for the majority of total injuries across all 3 seasons (Table III), while indirect injuries occurred less frequently. Sixty-six per cent and $62 \%$ of all injuries to backline players and forwards respectively were direct injuries. Fifty-six per cent of the players injured in 2001 , and $60 \%$ in 2003 , occupied backline positions. Injury rates amongst backline players in 2003 had decreased by $52 \%$ (4.7 v. 2.2) since 2001, and 42\% (3.8 v. 2.2) since 2002 $(p<0.0001)$. Amongst forward players, the injury rate decreased by $59 \%$ from 3.7 injuries per 1000 hours at risk in 2001 and 2002 to 1.5 injuries per 1000 hours at risk in $2003(p<0.0001)$. 


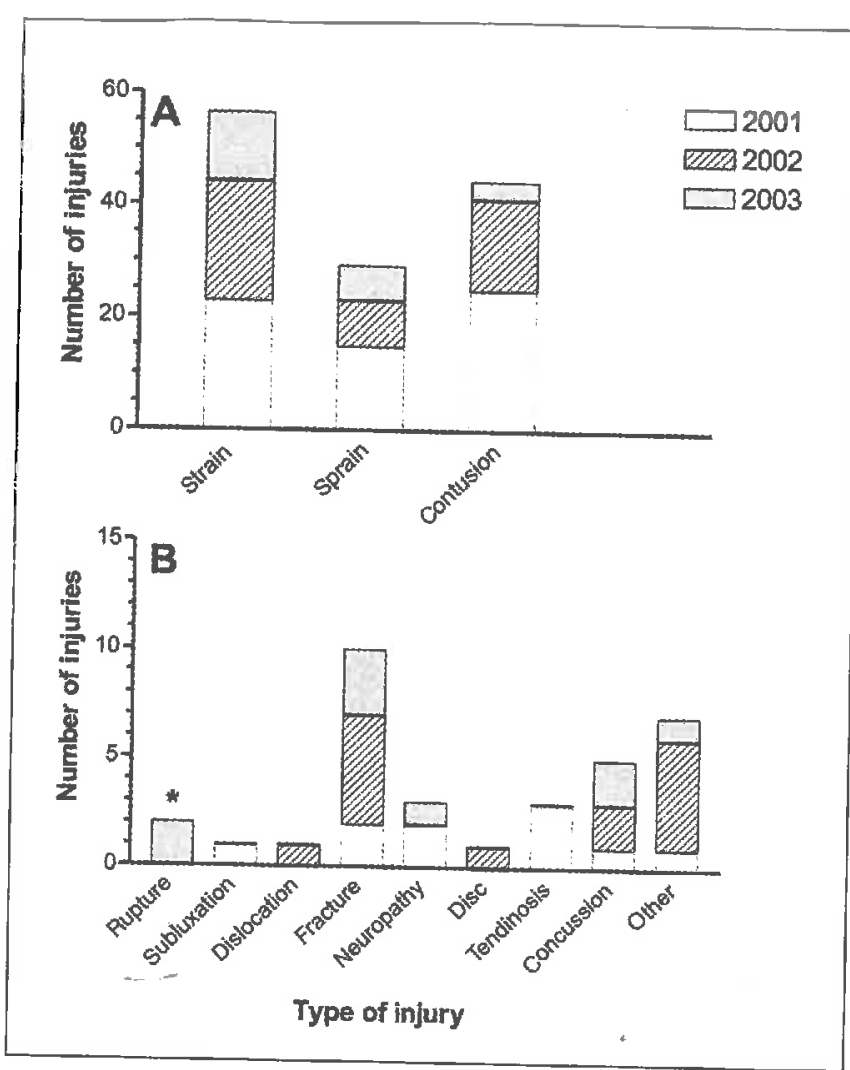

Fig. 2. Type of injuries sustained during each season ("p < 0.05; Rupture 2003 v. Rupture 2001 and Rupture 2002 (B).

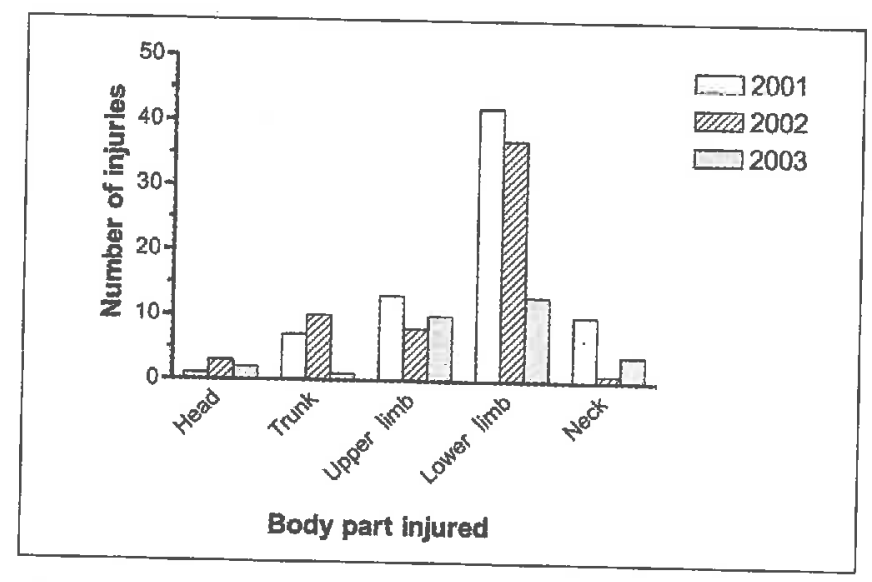

Fig. 3. Body parts injured during all three seasons.

Strains $(N=56)$, sprains $(N=29)$ and contusions $(N=44)$ accounted for the majority of injuries each season (Figure. 2A). Injuries such as fractures and concussions occurred less frequently and accounted for less than $30 \%$ of total injuries each season (Fig. 2B). Fig. 3 shows the breakdown of injuries according to the body part injured. Injuries to the lower limb accounted for $57 \%, 62 \%$ and $43 \%$ of total injuries in 2001, 2002 and 2003 respectively.

\section{Discussion}

The aim of this study was to report on the nature and incidence of injuries in a South African Currie Cup rugby team over 3 consecutive seasons. There was a tendency for the incidence of injuries to increase as the season progressed, with the majority of injuries occurring in the months of August and September each year. This is similar to other studies which have reportêd a higher incidence of injury in the early or pre-season period, and again in the final third of the season. $5,16,23,24$ This was previously attributed to fatigue and accumulative microtrauma. ${ }^{7,17}$ It should also be noted that many of the elite players leave the Currie Cup rugby team to tour with the South African national team and compete in the Tri-Nations tournament during the month of July, increasing their exposure time to both training and matches. Subsequently many amateur players are drafted into the side. The injury management at club level is inadequate and many of these amateur players have pre-existing injuries contributing to the increased number of injuries occurring later in the season.

Secondly, contrary to other studies, ${ }^{21}$ we found that injury rate decreased over the 3 consecutive seasons. It has been shown in rugby league that when players were given an insufficient off-season to recover from their injuries the incidence of injuries was incréased. ${ }^{21}$ In addition, Lee at al. ${ }^{18}$ have shown that for each week of additional pre-season training a player attends, there is a $3.9 \%$ increase in relative risk of injury. The team in this study has a short off-season ( -5 weeks), with many of the professional players having approximately a month off. Despite this, the number of injuries decreased each season. We suggest that this is due to 4 preventive strategies introduced by the coaching and medical support staff in an attempt to reduce the number of injuries sustained by the team s players.

Although the design of this study does not establish cause and effect relationships, it is reasonable to examine the changes in training and medical support over the 3 years and to theorise about the role they might have played in the changes in injury incidence. Accordingly, the first explanation was that a full-time physiotherapist was employed by the team for the first time in 2001 . This allowed for better management of injuries both during the season and during the off-season. Secondly, the team physiotherapist introduced regular pre- and post-injury musculoskeletal evaluations to identify weaknesses before injuries occurred and prevent complications from pre-existing injuries.

Thirdly, the coaching staff changed their training strategy for the 2003 season. The volume of training did not change significantly from 2001 and 2002 but the focus of the training sessions shifted away from exclusively power and strength training towards rehabilitative and technical training. Sessions were split into two shorter sessions, with a recovery period between sessions. This allowed the coach to introduce more technical exercises as players were less fatigued and better able to focus. Several rugby league studles have shown that the number of injuries increases as the volume and intensity of training increase, ${ }^{8,9}$ possibly as a result of increased fatigue. O Connor and Crowe ${ }^{20}$ have suggested that the peripheral vision of rugby players may be 
affected by fatigue, and this may contribute to the increase in injury incidence with high-intensity training. ${ }^{11}$ This suggests that the change in training strategy, by introducing a recovery period between sessions and reducing cumulative fatigue, may have contributed to the decrease in injury rate, particularly in 2003.

Lastly, in the 2003 season a recovery day, emphasising rehabilitation and light recovery training, was introduced on Mondays following a match. This gave players time to rest and receive comprehensive treatment for injuries. In addition, it prevented the possibility of players training the whole week while still carrying minor injuries received in the weekend s game. If, as suggested, player fatigue and cumulative microtrauma ${ }^{6}$ are contributing factors to injuries, this recovery day may have contributed to the decrease in the occurrence of both

The third finding in this study was that the lower limb sustained the highest incidence of injuries. This is consistent with some, ${ }^{2,15,23}$ but not all, studies of rugby union, as previous studies have shown a higher proportion of head and neck injuries. ${ }^{1.14,24}$ The most commonly occurring injuries were strains, sprains and contusions which is consistent with previous studies of rugby union. ${ }^{1,2,24}$

In conclusion, the observed Currie Cup rugby team sustained the highest number of injuries later in the season. The lower limb was the most injured body part, with the most commonly occurring injuries being strains, sprains and contusions. Injury rate decreased over the 3 consecutive seasons despite a short off-season $(p<0.0001)$. This suggests that preventive strategies implemented by team coaches, conditioning coaches and physiotherapists may reduce the number of injuries in rugby union, and continuous evaluation and management of training strategies is advised.

\section{References}

1. Bathgate A, Best JP, Craig G, Jamieson M. A prospective study of injuries to elite Australian rugby union players. Br J Sports Med 2002;36:265-9.

2. Bird YN, Waller AE, Marshall SW, Alsop JC, Chalmers DJ, Gerrard DF. The New Zealand Rugby Injury and Performance Project: V. Epidemiology of a season of rugby injury. Br J Sports Med 1998;32:319-25.

3. Bruckner P, Khan K. Part A fundamental principles; Sports injuries. In: Bruckner P, Khan K, eds. Clinical Sports Medicine. Sydney: McGraw-Hill, 2002: 9-29.
4. Chalmers DJ, Simpson JC, Depree R. Tackling rugby injury: lessons learned from the implementation of a five-year sports injury prevention program. J Sci Med Sport 2004;7:74-84.

5. Clark DR, Roux C, Noakes TD. A prospective study of the incidence and nature of injuries to adult rugby players. $S$ Afr Med $J$ 1990;77:559-62.

6. Estell J, Shenstone B, Barnsley L. Frequency of injuries in different agegroups in an elite rugby league club. Australian Journal of Science and Medicine in Sport 1995;27:95-7.

7. Gabbett TJ. Incidence, site, and nature of injuries in amateur rugby league over three consecutive seasons. Br J Sports Med 2000;34:98-103.

8. Gabbett TJ. Incidence of injury in semi-professional rugby league players Br J Sports Med 2003;37:36-43.

9. Gabbett TJ. Influence of training and match intensity on injuries in rugby league. $J$ Sports Sci 2004;22:409-17

10. Garraway WM, Lee AJ, Huttón SJ, Russell EB, Macleod DA. Impact of professionalism on injuries in rugby union. $B r J$ Sports Med 2000;34:34851.

11. Garraway WM, Lee AJ, Macleod DA, Telfer JW, Deary $\mathrm{W}$, Murray GD. Factors influencing tackle injuries in rugby union football. Br J Sports Med 1999;33:37-41.

12. Gibbs N. Injuries in professional rugby league. A three-year prospective study of the South Sydney Professional Rugby League Football Club. Am $J$ Sports Med 1993;21:696-700.

13. Gissane C, Jennings DC, Cumine AJ, Stephenson SE, White JA Differences in the incidence of injury between rugby league forwards and backs. Australian Journal of Science and Medicine in Sport 1997;29:91-4

14. Holtzhausen LJ, Schwelinus MP, Jakoet I, Pretorius AL. Pre-season assessments of South African players in the 1999 rugby Super 12 competition. South African Journal of Sports Medicine 2002;9(2):15-21.

15. Jakoet I, Noakes TD. A high rate of injury during the 1995 Rugby World Cup. S Afr Med J 1998;88:45-7.

16. Kew T, Noakes TD, Kettles AN, Goedeke RE, Newton DA, Scher AT. A retrospective study of spinal cord injuries in Cape Province rugby players, 1963 - 1989. Incidence, mechanisms and prevention. S Afr Med 1991;80:127-33.

17. Kibbler WB, Chandler TJ. Musculoskeletal and orthopedic considerations. In: Kreider RB, Fry AC, O'Toole ML, eds. Overtraining in Sport Champaign,lll.: Human Kinetics, 1998: 169-90.

18. Lee Ad, Garraway WM, Arneil DW. Influence of preseason training, fitness, and existing injury on subsequent rugby injury. Br J Sports Med 2001;35:412-7.

19. Lequesne MG, Dang N, Lane NE. Sport practice and osteoarthritis of the limbs. Osteoarthritis Cartilage 1997;5:75-86.

20. O'Connor D, Crowe M. Visual reaction time and peripheral vision in professional rugby players. J Sports Sci 1999;17:830.

21. Phillips $L H$, Standen $P J$, Batt ME. Effects of seasonal change in rugby league on the incidence of injury. Br J Sports Med 1998;32:144-8.

22. Quarrie KL, Alsop JC, Waller AE, Bird YN, Marshall SW, Chalmers DJ. The New Zealand rugby injury and performance project. VI. A prospective cohort study of risk factors for injury in rugby union football. $\mathrm{Br} J$ Sports Med 2001;35:157-66.

23. Roux CE, Goedeke R, Visser GR, van ZyI WA, Noakes TD. The epidemiology of schoolboy rugby injuries. S Afr Med J 1987;71:307-13.

24. Targett SG. Injuries in professional Rugby Union. Clin $J$ Sport Med 1998;8:280-5. 